\title{
Effect of wortmannin and phorbol ester on Paramecium fluid-phase uptake in the presence of transferrin
}

\author{
J. Wiejak, L. Surmacz, and E. Wyroba
}

Department of Cell Biology, Nencki Institute of Experimental Biology, 3 Pasteur Street, 02-093 Warsaw, Poland

Accepted: 18/9/01

Key words: Lucifer Yellow uptake, wortmannin, phorbol ester, transferrin

\section{SUMMARY}

The kinetics of the uptake of the fluid phase marker Lucifer Yellow (LY), and its alteration by wortmannin, an inhibitor of phosphatidylinositol-3 kinase (PI-3K), and the PKC modulators: GF $109203 \mathrm{X}$, an inhibitor, and phorbol ester, an activator was studied in eukaryotic model Paramecium aurelia. Spectrophotometric quantification of LY accumulation was performed in the presence or absence of transferrin, a marker of receptor-mediated endocytosis. Internalization of LY showed a curvilinear kinetics: the high initial rate of LY uptake (575 ng LY/ mg protein /hr) decreased almost 5-fold within $15 \mathrm{~min}$, reaching plateau at $126 \mathrm{ng} / \mathrm{mg}$ protein $/ \mathrm{hr}$. Transferrin induced a small increase $(7.5 \%)$ in the fluid phase uptake rate (after $5 \mathrm{~min}$ ) followed by a small decrease at longer incubation times. Lucifer Yellow and transferrin (visualized by streptavidin-FITC) were localized in Paramecium by 3-D reconstruction by confocal microscopy. LY showed a scattered, diffuse fluorescence typical of fluid phase uptake whereas transferrin accumulated in membrane-surrounded endosomes.

Wortmannin did not affect LY accumulation but decreased it when transferrin was present in the incubation medium. This suggests an effect on the transferrin uptake pathway, presumably on the stage of internalization in "mixing" endosomes to which transferrin and LY were targeted.
Phorbol ester diminished LY accumulation by $22 \%$ and this effect persisted up to $25 \mathrm{~min}$ of incubation. PKC inhibitor did not affect LY uptake. However, in the presence of transferrin, the LY uptake increased within the first 15 minutes followed by a rapid $20 \%$ decrease in comparison to the control. Such an effect of PKC modulators suggests that PMA action on fluid phase uptake is not directly mediated by PKC.

\section{INTRODUCTION}

Controversial data may be found in the literature concerning uptake mechanisms as well as the relationship between the fluid phase and receptor-mediated endocytosis (RME) even when the same system was studied. Ellinger et al. (1998) using free-flow electrophoresis reported that in the rat liver the fluid phase marker, FITC-dextran was found in endosomes with the same electrophoretic mobility as early sorting endosomes labeled by the asialoorosomucoid (ASOR) or by transferrin, both of which enter via RME. With increasing internalization time, FITC-dextran-labeled compartments co-localized with late, ASOR-containing endosomes. On the other hand, Oka \& Weigel (1989), Stromhaug et al. (1997) and Synnes et al. (1999) showed that fluid-phase and 
receptor-mediated endocytosis markers in hepatocytes enter the cells via different routes. There is a growing body of evidence that the content of the pinosomes (formed during the fluid phase uptake) and endosomes - "mix" up inside of the cell and the ligands internalized by both pathways enter the same endosomes (Spiro et al. 1996, Ellinger et al. 1998, Synnes et al. 1999).

Phosphatidylinositol 3-kinase (PI-3K) plays an important role in endosome fusion (Jones et al. 1998, Simonsen et al. 1998, Corvera et al. 1999). On the other hand, phorbol esters (PMA) may promote endocytosis by activating a factor involved in endosome fusion acting via PKC or yet not identified protein factor(s) (Aballay et al. 1999).

Paramecium has the components required for the classical "receptor - mediated" endocytic pathway (Allen, 2000). Coated pits take up HRP (Allen et al. 1980) and ferritin (Wyroba, 1988). We have also shown that Paramecium internalized LDL (Wyroba et al. 1988) when it was used as a model cell to follow the uptake and retention of the sensitibilizers used in the photodynamic therapy of tumors (Croce et al. 1990, 1992). Our recent finding that Paramecium posseses a homologue of mammalian dynamin 2 (Surmacz et al. 2001) - involved in coated vesicles scission brought new evidence for the existence of a receptor-mediated pathway in this cell. We therefore attempted to quantify the fluid phase uptake in the absence and presence of transferrin - a receptor-mediated endocytosis marker (Veithen et al. 1998, Wassenberg et al. 1999, de Figueiredo and Soares, 2000).

In this paper, we present the results of our studies on fluid-phase intake measured by LY accumulation and the effects of wortmannin, an inhibitor of PI-3K and PMA, as potential modulators of this pathway in the presence of transferrin. To better understand the influence of PMA, we also used the protein kinase C inhibitor, GF 109203 X, in the quantifications performed.

\section{MATERIALS AND METHODS}

\section{Cells}

Paramecium aurelia cells (5-day-old axenic cultures, strain 299s) were cultivated, collected and starved aseptically for $18 \mathrm{~h}$ as described previously (Wyroba, 1987) so as to be devoid of autofluorescence (Wyroba and Bottiroli, 1981).

\section{Modulation of internalization}

The following reagents, that modulate the process of internalization, were used:

1. GF 109203 X (bisindolylmaleimide, Tocris Cookson), a very strong and selective protein kinase C inhibitor (Toullec et al. 1991).

2. PMA (phorbol 12-myristate 13-acetate, Sigma), shown previously to stimulate Paramecium phagocytosis (Wyroba 1987).

3. Wortmannin (Sigma), phosphatidylinositol 3kinase inhibitor (Arcaro and Wymann 1993).

These reagents were dissolved in DMSO (Sigma), the concentration of which in the reaction mixture was not higher than $0.9 \%$ (to exclude its effect on cell metabolism). Control samples contained identical amounts of DMSO without the reagents.

To establish the optimal concentration of these reagents, preliminary experiments were performed to control the cell viability. Additional control of PMA effectiveness was performed by testing the phagocytosis of latex beads.

\section{Fluorimetric assay}

Lucifer Yellow CH (Sigma) accumulation was quantified at $20^{\circ} \pm 2^{\circ} \mathrm{C}$. Cells were treated with wortmannin $(50 \mathrm{nM})$, PMA $(0.8 \mu \mathrm{M})$, GF 109203 $\mathrm{X}(0.8 \mu \mathrm{g} / \mathrm{ml})$ or transferrin-biotin labeled (100 $\mu \mathrm{g} / \mathrm{ml}$, Sigma) in the presence of LY $(25 \mu \mathrm{g} / \mathrm{ml})$. After various times of incubation, aliquots of the cells were withdrawn from the medium and immediately placed in a 150 times excess of cold $\left(4^{\circ} \mathrm{C}\right)$ phosphate-saline buffer (= MSS, Soldo et al. 1966) followed by centrifugation $(600 \mathrm{x} \mathrm{g})$. The cell pellet was subjected to the next identical washing procedure to remove free label. The last washing supernatant and cell pellet was collected for assay of LY. Pinocytosed LY was assayed by combining $2 \mathrm{ml}$ of the compact pellet with $0.2 \mathrm{ml}$ of $0.1 \%$ Triton X-100 (Sigma), vortexing to obtain a homogenate and reading the fluorescence in a Perkin-Elmer Luminescence Spectrometer LS-5B at excitation $430 \mathrm{~nm}$ and emission at $540 \mathrm{~nm}$. The standard curve of LY fluorescence was estimated at each series of experiments. The cell fluorescence (determined by subtraction of fluorescence of supernatants from that of cell lysates) was expressed per mg of cell protein and related to cell density and volume.

\section{Protein determination}

Protein content was determined by the Lowry method (1951) and assayed spectrophotometrical- 
ly at $750 \mathrm{~nm}$ using bovine albumin (fraction $\mathrm{V}$, Calbiochem) as a standard.

\section{Confocal microscopy}

Paramecium cells incubated for 15 min either with LY $(25 \mu \mathrm{g} / \mathrm{ml})$ or biotinylated transferrin $(100 \mu \mathrm{g} / \mathrm{ml})$ were analyzed. The latter samples were next treated with FITC-streptavidin $(17.2 \mu \mathrm{g} / \mathrm{ml}$, Sigma) for 10 min. After the treatment, all the samples were immediately fixed in freshly prepared $4 \%$ paraformaldehyde (Sigma) for $15 \mathrm{~min}$, washed three times in 0.01 M PBS, mounted in 2.5\% DABCO (Sigma) and analyzed in a CLSM Phoibos 1000 confocal microscope (Molecular Dynamics, USA). The images and the 3 $\mathrm{D}$ reconstructions were performed as described previously (Wyroba et al. 1996).

\section{RESULTS}

Cells internalized LY in a time-dependent manner and the rate of accumulation was not linear, i.e. it decreased with increasing time of incubation (Fig. 1). The kinetics of LY uptake was characterized by a high initial uptake rate of $575 \mathrm{ng} / \mathrm{mg}$ protein/hr followed by slowing to $126 \mathrm{ng} / \mathrm{mg}$ protein/hr within $15 \mathrm{~min}$ at $25 \mu \mathrm{g} / \mathrm{ml}$ of LY in the incubation medium (Fig. 1). Accumulation of LY in the cells was linear up to $50 \mu \mathrm{g} / \mathrm{ml}$ of LY in the medium (Fig. 2).

Transferrin induced a $7.5 \%$ increase in LY uptake rate (after $5 \mathrm{~min}$ ) followed by a similar decrease as measured by LY accumulation (Fig. 1). Wortmannin itself had no initial effect on LY accumulation but it

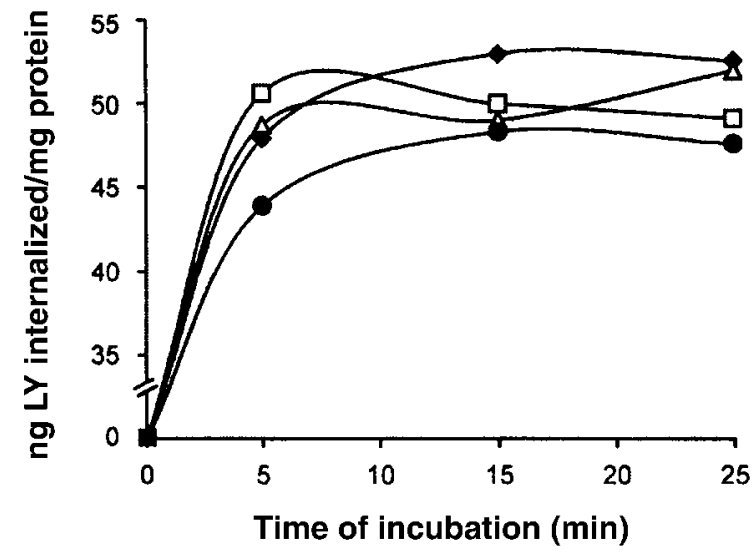

Fig. 1 - Accumulation of Lucifer Yellow by Paramecium cells in the presence of transferrin $(\square)$, wortmannin $(\triangle)$ or transferrin and wortmannin $(\mathbf{)})$ in comparison to the control $(\checkmark)$. Mean value of $n=4$, where the standard deviation was $\pm 6-9.6$. slightly diminished its uptake only after 15 minutes of incubation. When wortmannin was added with transferrin, LY accumulation was decreased by 89\% at all the studied time points (Fig. 1).

The localization of LY, a fluid-phase tracer, and transferrin, a receptor-mediated endocytosis marker, was studied in Paramecium cells using confocal microscopy. We have observed that LY showed a scattered, diffuse fluorescence in the cells - typical for fluid phase uptake (Fig. 3A), whereas transferrin was accumulated in the membrane-surrounded endosomes (Fig. 3B), which was also evidenced by a three-dimensional reconstruction obtained from the series of 14 optical sections (Fig. 3C, D).

Phorbol ester, an activator of protein kinase $\mathrm{C}$, reduced the fluid phase uptake by $22 \%$ and this effect persisted for up to $25 \mathrm{~min}$, whereas the PKC inhibitor (GF $109203 \mathrm{X}$ ) did not affect LY accumulation (Fig. 4A). In the presence of transferrin, PMA effect was similar, but slightly lower (Fig. 4 B) - consistently with the influence of transferrin on LY uptake shown in Fig. 1. On the other hand, PKC inhibitor added simultaneously with transferrin increased the fluid phase uptake within the first 15 minutes of incubation followed by a rapid $20 \%$ decrease in comparison to the control (Fig. 4B).

We estimated that the total volume of LY accumulated within 5 min was $0.039-0.04 \mathrm{pl} /$ cell in the control samples.

\section{DISCUSSION}

There are many properties making Lucifer Yellow, a fluorescent disulfonic acid anionic dye, a useful fluid phase marker such as resistance to bleaching, lack of toxicity at the concentrations required for quantification of fluid phase endocytosis, absence of cellular metabolism and interaction with the cell membrane (McKinnley and Wiley, 1988).

We quantified spectrophotometrically the accumulation of LY in Paramecium and studied the effects of the modulators of two kinases: PKC (phorbol ester, GF 109203 X) and PI 3-kinase (wortmannin) in the presence and absence of transferrin - a marker of the receptor-mediated pathway (Schmid et al. 1988, Woods et al. 1989, Sandvig and van Deurs 1990).

The LY accumulation in Paramecium was in the range of 50-60 ng/mg protein, i.e. 4-6 times lower than that observed in microvessel endothelial cells (Guillot et al. 1990) and macrophages (Swanson 


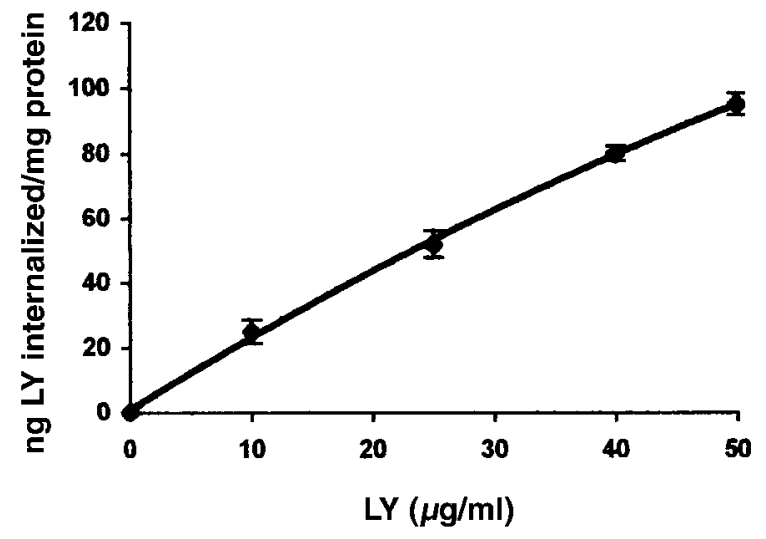

Fig. 2 - Concentration dependance of LY accumulation in Paramecium cells after incubation for $15 \mathrm{~min}$. Mean values $\pm \mathrm{SD}(\mathrm{n}=3)$ are shown

1989). However, the rate of influx $(0.44 \mathrm{pl} / \mathrm{cell} / \mathrm{hr})$ was comparable to other cell types as that observed by Swanson (1989) on macrophages $(0.38 \mathrm{pl} /$ cell / hr) and similar to sucrose uptake in 3T3-L1 adipocytes (Frost et al. 1989) and [ $\left.{ }^{3} \mathrm{H}\right]-\mathrm{Gal}$ intake in Dictiostelium discoideum (Thilo and Vogel 1980), which are in the range of $0.12-0.84 \mathrm{pl} / \mathrm{cell} / \mathrm{hr}$. The high initial rate of LY uptake of $575 \mathrm{ng} / \mathrm{mg}$ protein/ hr decreased to $22 \%$ within the next 20 minutes of incubation. Interestingly, such an effect was also observed by Swanson (1989) on macrophages. In immortalized cerebral endothelial cells, LY accumulation was also curvilinear with an initial rate of 807 ng/ mg protein/ hr (Deli et al. 2000), i.e. higher than determined in Paramecium. However, the LY con-
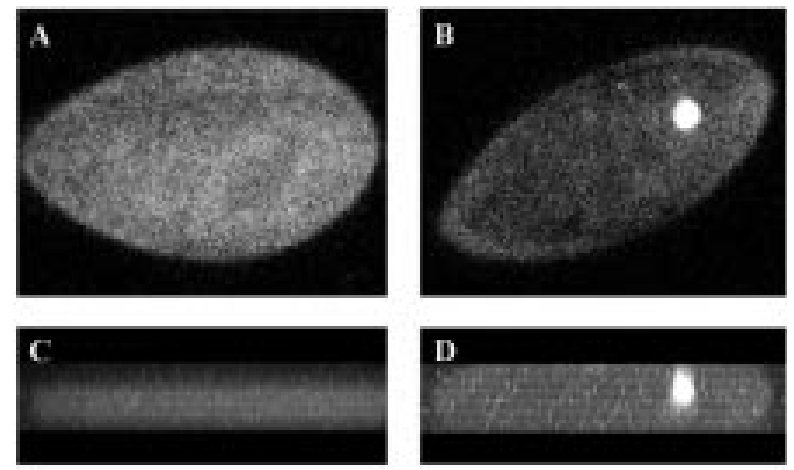

Fig. 3 - Confocal localization of LY (A) and transferrin (B) in Paramecium. Transferrin was localized with FITC-streptavidin as described in Materials and Methods. Three-dimensional reconstructions of distribution of $\mathrm{LY}(\mathrm{C})$ and transferrin (D). The images were obtained from the series of 14 optical sections (a $90^{\circ}$ projection) of the maximum intensity look-through reconstruction. Bar, $20 \mu \mathrm{m}$. centration in the incubation medium was 20 -fold higher than that applied by us.

PI 3-kinase activity is known to play a role in intracellular trafficking, particularly from endosomes to lysosomes, and may regulate an early step in receptor-mediated endocytosis (Brunskill et al. 1998, Davol et al. 1999).

Wortmannin, a potent inhibitor of PI 3-kinase, inhibits receptor sorting and/or vesicle budding required for delivery of endocytosed material to "mixing" endosomes (Spiro et al. 1996). The presence of wortmannin-sensitive enzymes was shown at three distinct steps of the endocytic cycle in Chinese hamster ovary cells when transferrin uptake was monitored (Martys et al. 1996).

Wortmannin did not affect LY accumulation in Paramecium, but decreased it when transferrin was present in the incubation medium. This may indicate an effect on a receptor- mediated pathway, presumably on the stage of the uptake in "mixing" endosomes to which transferrin and LY are targeted. In fact, we have observed a co-localization of Texas Red-conjugated transferrin with Lucifer Yellow in the endosomes of similar shape and dimension (Surmacz, Wiejak and Wyroba, unpublished) as those shown in Fig. 2 where transferrin was visualized by streptavidin-FITC.

It seems that the uptake of transferrin is under negative control of PKC: PKC inhibitor (GF $109203 \mathrm{X}$ ) increased LY accumulation in the presence of transferrin and after 25 min incubation i.e. coinciding with the time course of endosome cycling in Paramecium (Fok et al. 1982) induced rapid decrease of LY uptake (to $70 \%$ of the initial value). This is in agreement with the results of Ellinger et al. (1998), that fluid-phase marker containing endosomes co-localized with transferrin-labeled endosomes in hepatocytes.

Phorbol esters can alter several steps of intracellular trafficking (Aballay et al. 1999) and have multiple effects on normal endocytosis (PelchenMatthews et al. 1993). PMA promotes endocytosis by activating a factor involved in endosome fusion acting via $\mathrm{PKC}$ or not yet identified protein factor(s) (Aballay et al. 1999).

We have observed that PMA decreased LY accumulation and PKC inhibitor did not affect this process. This suggests that the PMA influence on fluid phase endocytosis is probably not mediated by PKC signalling but may be resulting from its effect on the other factors - discussed above reported by Aballay et al. (1999). 
A
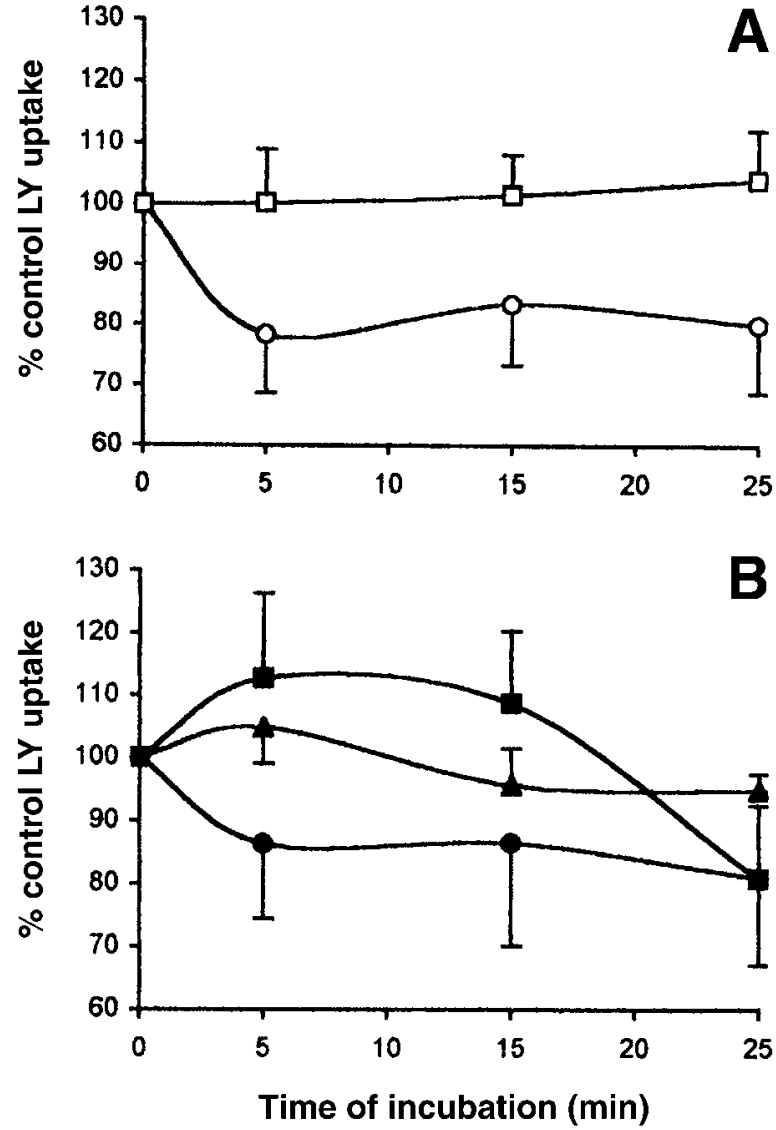

Fig. 4 - Effect of phorbol ester $(\bigcirc, \bigcirc)$ and GF 109203 X, a PKC inhibitor $(\square, \square)$, on Lucifer Yellow uptake in the absence (A) or presence of transferrin $(\mathbf{A})(B)$. The values are expressed as percentage of control. The mean values of four (A) and three (B) independent experiments \pm S.D, respectively, are shown.

Paramecium was a subject of studies on endo- and exocytic processes (Allen and Fok 1980, 2000, Ziessenis and Plattner 1985, Wyroba 1987, 1991, Subramanian et al. 1994), but both the regulation of endocytic routes and a relationship between pinocytosis and RME uptake requires further investigation.

\section{ACKNOWLEDGEMENTS}

This research was supported by the Committee for Scientific Research /KBN/ - grant no 6 PO4C 07119 and statutory funds to Nencki Institute.

\section{REFERENCES}

Aballay A., Stahl P.D., and Mayorga L.S.: Phorbol ester promotes endocytosis by activating a factor involved in endosome fusion. J. Cell Sci. 112, 2549-2557, 1999.

Allen R.D., and Fok A.K.: Membrane recycling and endocytosis in Paramecium confirmed by horseradish peroxidase pulse-chase studies. J. Cell. Sci. 45, 131-145, 1980

Allen R.D., and Fok A.K.: Membrane trafficking and processing in Paramecium. Int. Rev. Cytol. 198, 277-318, 2000.

Arcaro A., and Wymann M.P.: Wortmannin is a potent phosphatidylinositol 3-kinase inhibitor: the role of phosphatidylinositol 3,4,5-trisphosphate in neutrophil responses. Biochem. J. 296, 297-301, 1993

Brunskill N.J., Stuart J., Tobin A.B., Walls J., and Nahorski S.: Receptor-mediated endocytosis of albumin by kidney proximal tubule cells is regulated by phosphatidylinositide 3kinase. J. Clin. Invest. 101, 2140-2150, 1998.

Corvera S., D'Arrigo A., and Stenmark H.: Phosphoinositides in membrane traffic. Curr. Opin. Cell Biol. 11, 460-465, 1999.

Croce A.C., Wyroba E., and Bottiroli G.: Uptake and distribution of hematoporphyrin-derivatives in the unicellular eukaryote Paramecium. J. Photochem. Photobiol. B 6, 405-417, 1990.

Croce A.C., Wyroba E., Cuzzoni C., and Bottiroli G.: Localization and persistance of rose bengal in unicellular eukaryotes and in experimental tumor. Excerpta Medica International Congress Series, Elsevier Science Publishers B.V., Netherlands, pp. 737-741, 1992.

Davol P.A., Bizuneh A., and Frackelton A.R.Jr.: Wortmannin, a phosphoinositide 3-kinase inhibitor, selectively enhances cytotoxicity of receptor-directed-toxin chimeras in vitro and in vivo. Anticancer Res. 19, 1705-1713, 1999.

Deli MA., Abraham C.S., Takahata H., Katamine S., and Niwa M.: Pentosan polysulfate regulates scavenger receptor-mediated, but not fluid-phase, endocytosis in immortalized cerebral endothelial cells. Cell. Molec. Neurobiol. 20, 731-745, 2000.

Ellinger I., Klapper H., and Fuchs R.: Fluid-phase marker transport in rat liver: free-flow electrophoresis separates distinct endosome subpopulations. Electrophoresis 19, 1154-1161, 1998.

de Figueiredo R.C., and Soares M.J.: Low temperature blocks fluid-phase pinocytosis and receptor-mediated endocytosis in Trypanosoma cruzi epimastigotes. Parasitol. Res. 86, 413418, 2000.

Fok A.K., Lee Y., and Allen R.D.: The correlation of digestive vacuole $\mathrm{pH}$ and size with the digestive cycle in Paramecium caudatum. J. Protozool. 29, 409-414, 1982.

Frost S.C., Lane M.D., and Gibbs E.M.: Effect of phenylarsine oxide on fluid phase endocytosis: further evidence for activation of the glucose transporter. J. Cell. Physiol. 141, 467-474, 1989.

Guillot F.L., Audus K.L., and Raub T.J.: Fluid-phase endocytosis by primary cultures of bovine brain microvessel endothelial cell monolayers. Microvasc. Res. 39, 1-14, 1990. 
Jones A.T., Mills I.G., Scheidig A.J., Alexandrov K., and Clague M.J.: Inhibition of endosome fusion by wortmannin persists in the presence of activated Rab5. Mol. Biol. Cell 9, 323-332, 1998

Lowry O.H., Rosebrough N.J., Farr A.L., and Randall R.J.: Protein measurement with the Folin phenol reagent. J. Biol. Chem. 193, 265-275, 1951.

Martys J.L., Wjasow C., Gangi D.M., Kielian M.C., McGraw T.E., and Backer J.M.: Wortmannin-sensitive trafficking pathways in Chinese hamster ovary cells. Differential effects on endocytosis and lysosomal sorting. J. Biol. Chem. 271, 10953-10962, 1996.

McKinley D.N., and Wiley H.S.: Reassement of fluid-phase endocytosis and diacytosis in monolayer cultures of human fibroblasts. J. Cell. Physiol. 136, 389-397, 1988.

Oka J.A., and Weigel P.H.: The pathways for fluid phase and receptor-mediated endocytosis in rat hepatocytes are different but thermodynamically equivalent. Biochem. Biophys. Res. Commun. 159, 488-494, 1989.

Pelchen-Matthews A., Parsons I.J., and Marsh M.: Phorbol ester-induced downregulation of CD4 is a multistep process involving dissociation from p56lck, increased association with clathrin-coated pits, and altered endosomal sorting. J. Exp. Med. 178, 1209-1222, 1993.

Sandvig K., and van Deurs B.: Selective modulation of the endocytic uptake of ricin and fluid phase markers without alteration in transferrin endocytosis. J. Biol. Chem. 265, 63826388, 1990.

Schmid S.L., Fuchs R., Male P., and Mellman I.: Two distinct subpopulations of endosomes involved in membrane recycling and transport to lysosomes. Cell 52, 73-83, 1988.

Simonsen A., Lippe R., Christoforidis S., Gaullier J.M, Brech A., Callaghan J., Toh B.H., Murphy C., Zerial M., and Stenmark H.: EEA1 links PI(3)K function to Rab5 regulation of endosome fusion. Nature 394, 494-498, 1998.

Soldo A.T., Godoy G.A., and van Wagtendonk W.J.: Growth of particle-bearing and particle-free Paramecium aurelia in axenic culture. J. Protozool. 13, 492-497, 1966.

Spiro D.J., Boll W., Kirchhausen T., and Wessling-Resnick M.: Wortmannin alters the transferrin receptor endocytic pathway in vivo and in vitro. Mol. Biol. Cell 7, 355-367, 1996.

Stromhaug P.E., Berg T.O., Gjoen T., and Seglen P.O.: Differences between fluid-phase endocytosis (pinocytosis) and receptor-mediated endocytosis in isolated rat hepatocytes. Eur. J. Cell Biol. 73, 28-39, 1997.

Subramanian S.V., Wyroba E., Andersen A.P., and Satir B.H.: Cloning and sequencing of parafusin, a calcium-dependent exocytosis-related phosphoglycoprotein. Proc. Natl. Acad. Sci. USA 91, 9832-9836, 1994

Surmacz L., Wiejak J., and Wyroba E.: Cloning and sequencing of Paramecium dynamin gene fragment. Eur. J. Biochem. 268 (Suppl. 1), 58, 2001
Swanson J.A.: Phorbol esters stimulate macropinocytosis and solute flow through macrophages. J. Cell Sci. 94, 135-142, 1989.

Synnes M., Prydz K., Lovdal T., Brech A., and Berg T.: Fluid phase endocytosis and galactosyl receptor-mediated endocytosis employ different early endosomes. Biochim. Biophys. Acta 1421, 317-328, 1999.

Thilo L., and Vogel G.: Kinetics of membrane internalization and recycling during pinocytosis in Dictyostelium discoideum. Proc. Natl. Acad. Sci. USA 77, 1015-1019, 1980.

Toullec D., Pianetti P., Coste H., Bellevergue P., Grand-Perret T., Ajakane M, Baudet V., Boissin P., Boursier E., Loriolle F., et al.: The bisindolylmaleimide GF $109203 \mathrm{X}$ is a potent and selective inhibitor of protein kinase C. J. Biol. Chem. 266, 15771-15781, 1991.

Veithen A., Amyere M., Van Der Smissen P., Cupers P., and Courtoy P.J.: Regulation of macropinocytosis in v-Src-transformed fibroblasts: Cyclic AMP selectively promotes regurgitation of macropinosomes. J. Cell Sci. 111, 2329-2335, 1998.

Wassenberg J.J., Dezfulian C., and Nicchitta C.V.: Receptor mediated and fluid phase pathways for internalization of ER Hsp90 chaperone GRP94 in murine macrophages. J. Cell Sci. 112, 2167-2175, 1999.

Woods J.W., Goodhouse J., and Farquhar M.G.: Transferrin receptors and cation-independent mannose-6-phosphate receptors deliver their ligands to two distinct subpopulations of multivesicular endosomes. Eur. J. Cell Biol. 50, 132-143, 1989.

Wyroba E., Bottiroli G, and Giordano P.: Autofluorescence of axenically cultivated Paramecium aurelia. Acta Protozool. 20, 165-170, 1981.

Wyroba E.: Stimulation of Paramecium phagocytosis by phorbol ester and forskolin. Cell. Biol. Rep. 11, 657-664, 1987.

Wyroba E.: Endocytosis of cationized ferritin in Paramecium cells. Inst. Phys. Conf. Ser. 93, 481-482, 1988.

Wyroba E., Croce A.C., and Bottiroli G.: Cellular uptake process of $\mathrm{HpD}$ studied in protozoan cells. Proc $10^{\text {th }}$ Congress on Photobiology, Israel, 86, 1988

Wyroba E.: Quantitation of fluid phase uptake in Paramecium. 1. Kinetics in the cells blocked in phagocytic activity. Cell Biol. Int. Rep. 15, 1207-1216, 1991.

Wyroba E., Pawlowska Z., Kobylanska A., Pluskota E., Maszewska M., Stec W.J., and Cierniewski C.S.: Internalization of oligodeoxynucleotides antisense to type-1 plasminogen activator inhibitor mRNA in endothelial cells - a threedimensional reconstruction by confocal microscopy. Biol. Cell 87, 37-44, 1996

Zieseniss E., and Plattner H.: Synchronous exocytosis in Paramecium cells involves very rapid $(<1 \mathrm{~s}$,) reversible dephosphorylation of a $65-\mathrm{kD}$ phosphoprotein in exocytosis competent strains. J. Cell Biol. 101, 2028-2035, 1985. 